\title{
Formas de la cultura alternativa: las 'veladas' y los festivales de las izquierdas uruguayas (Montevideo, 1920-1950)
}

\author{
The forms of alternative culture: the veladas and festivals of the Uruguayan left \\ (Montevideo, 1920-1950)
}

Rodolfo Porrini Beracochea*

Resumen: Este texto aborda la evolución de veladas y festivales, expresiones comunes de las izquierdas socialista, anarquista y comunista, en Montevideo entre 1920 y 1950. Además de picnics y deportes, cursos y conferencias, aquellas constituían expresiones de la cultura de los trabajadores en teatros y locales cerrados. Reunían fondos para la prensa obrera y los presos, siendo también ámbitos de sociabilidad y militancia que reunía a las familias en espacios de camaradería y "cultura". De expresiones muy completas (teatro, poesía, bailes, conferencias, cine) en el decenio de 1940 se fueron simplificando hasta casi desaparecer. Esto ocurría en medio de cambios culturales relevantes como el impacto masivo del cine y la radio, y la fuerza del "estado de bienestar" y su hegemonía, que las izquierdas y sus formas culturales intentaban disputar.

Palabras Clave: Izquierdas, veladas culturales, Montevideo, Uruguay

\begin{abstract}
This text approaches the evolution of the veladas (cultural gatherings) and festivals, common expressions of the socialist, anarchist and communist left in Montevideo between 1920 and 1950. In addition to picnics and sports, courses and conferences, those were expressions of the culture of workers in closed theaters and premises. They gathered funds for the working press and prisoners, also being areas of sociability and militancy that brought families together in spaces of camaraderie and "culture". These activities (theater, poetry, dances, conferences, cinema), which were intense in the 1940's, became simpler until almost disappearing. This happened in the midst of relevant cultural changes such as the massive impact of cinema and radio and the strength of the "welfare state" and its hegemony, which the left and their cultural forms tried to dispute.
\end{abstract}

Keywords: Left, cultural veladas, Montevideo, Uruguay

Recibido: 2 septiembre 2018 Aceptado: 29 octubre 2018

\footnotetext{
* Uruguayo. Autor. Doctor (Área Historia, UBA). Profesor Titular del Departamento de Historia Americana, Facultad de Humanidades y Ciencias de la Educación, Universidad de la República (Uruguay), e investigador en el Sistema Nacional de Investigadores (Agencia Nacional de Investigación e Innovación, ANII). roporrini@gmail.com
} 


\section{Introducción}

Este artículo se propone colocar el tema del "tiempo libre" como un aspecto importante en las prácticas de colectivos e individuos, así como en las estrategias de lucha, educación y sociabilidad por parte de las izquierdas en Uruguay. ${ }^{1}$ Se estudia a los anarquistas, socialistas y comunistas a lo largo de las tres décadas que van de 1920 a 1950 en la ciudad de Montevideo, extenso lapso que permite percibir permanencias y cambios así como proponer los factores que incidieron en los mismos.

Se busca resaltar la importancia del estudio de actividades en el 'tiempo libre de los trabajadores, discutiendo el minimizar o desconocer la temática. El tiempo libre se diferencia y está más allá del tiempo del trabajo, no solo asalariado, y nos interesa en particular el que transcurre entre el fin de éste y el sueño, y donde ocurren variadas prácticas cotidianas y expresiones de la cultura trabajadora.

Sin embargo, este tiempo no está desligado de aquel y de las condiciones (materiales, subjetivas, ideológicas) en que se desenvuelve.

Gareth Stedman Jones puso el centro de la discusión en el tema del "ocio" en los estudios de historia social y de la clase obrera, conectando con la pregunta ¿es posible analizar solo el tiempo libre sin vincularlo con el tiempo del trabajo? Según este autor "El tiempo libre está claramente condicionado por el tipo y el horario de trabajo". ${ }^{2}$ Reconoce el sentido de investigar el tiempo libre pero discute el hecho de volverlo un tema en sí, y advierte que el mayor dispositivo de "control social" capitalista es la relación salarial. También sostiene que las disputas alrededor del tiempo de ocio no encierran el antagonismo que conlleva la "lucha en las fábricas" y que "atribuir al esparcimiento una forma simbólica de conflicto de clases", lleva a las "teorías de la asimilación". 3 Si es verdad esa conexión directa -y de primacía- entre trabajo y el tiempo libre, también lo es que inciden las diversas ofertas (de empresarios, iglesias, políticos) y los gustos de quienes las reciben, las "necesidades" y las "costumbres en común" que vienen del pasado. Se puede apreciar cierta autonomía de la esfera cultural, integrada en un marco más amplio y una formación social concreta. Además, sin haber desarrollado una investigación fuerte sobre el "tiempo libre" y los procesos que allí se producen -de subordinación o insubordinación-, ¿por qué afirmar que el objetivo de un día festivo no es político y es "sólo divertirse"? ¿qué es "divertirse", no es una forma de "política" obrera, de ganar su tiempo? ¿por qué "no es una forma simbólica de conflicto de clases"?

Sin embargo, el tiempo libre no solo se estructura en relación al trabajo asalariado. En el marco de la división sexual del trabajo (en la esfera pública y la privada), el trabajo doméstico y de cuidados de las mujeres, no remunerado, en algunos casos se sumaba al trabajo asalariado, siendo una limitación más para ellas en el uso del "tiempo libre". ${ }^{4}$ Esa carga, en el tema que nos ocupa, podía verse acrecentada al participar en actividades de las izquierdas como las veladas, pues si la pareja tenía hijos muy posiblemente ellas debían estar a su cargo. Por lo tanto, la distribución y calidad de ese tiempo de no trabajo no es igual para hombres y mujeres, y no raramente, el disfrute del tiempo libre de los

\footnotetext{
${ }^{1}$ Entiendo por izquierdas una posición (política, ideológica, cultural) que critica, desafía -a veces enfrenta- al status quo y que propone modelos alternativos al capitalismo; puede incluir la socialización de los medios de producción y formas de vida comunitarias, socialistas y/o cooperativas. Junto a las izquierdas internacionales -anarquista, socialista y comunista- nacieron las izquierdas "nacionales" dentro de los denominados "partidos tradicionales" Nacional y Colorado, y la de raíz católica social, las que no serán estudiadas en este trabajo.

2 Gareth Stedman Jones, “¿Expresión de clase o control social? Crítica de las últimas tendencias de la historia social del 'ocio”" en Lenguajes de clase. Estudios sobre la historia de la clase obrera inglesa (1832-1982), Madrid, Siglo XXI, 1989, p.83.

3 Stedman Jones, “2. ¿Expresión de clase o control social? ...”, op.cit., p.84.

4 Agradezco especialmente a la feminista Eva Taberne su especial colaboración en torno a una mirada de género en algunos pasajes de este texto, eximiéndola totalmente de la interpretación general del mismo.
} 
primeros implicaba mayor carga de trabajo para estas últimas. En el caso uruguayo casi no existen investigaciones que tomen este tema desde una perspectiva de género para este periodo. ${ }^{5}$

Lo que ocurre en el tiempo libre, lo que se realiza en el hogar, en los espacios de la ciudad y el barrio, son formas y experiencias a conocer y estudiar, son parte de la cultura obrera y popular, la que hay que indagar y buscar sus sentidos, aquí me centraré en el espacio acotado de las veladas y festivales.

Si para la izquierda de principios del siglo XX ese tiempo libre debería ser, prioritariamente, el de la "militancia" -incluyendo la preparación ideológica para la nueva sociedad y la camaradería- para una mayoría de los trabajadores importaba diversas formas de esparcimiento, deporte, lecturas, sociabilidad y valores, algunos de los cuales eran compartidos por la izquierda y otros no.

En esta oportunidad se ha elegido enfocar empíricamente las prácticas de las izquierdas en espacios cerrados -cines y teatros, locales sociales y políticos- y especialmente en las veladas culturales y festivales. Se propone como hipótesis específica que estas formas de sociabilidad fueron mutando a partir de la influencia de cambios culturales más amplios como la masificación de la radio y el cine, influyendo en la transformación de las veladas en sus sentidos, formas y géneros, hasta desdibujarlas. Este proceso fue atravesado por la modernización cultural que también afectó a las izquierdas, y por la fuerza hegemónica del "estado de bienestar" nacional al que aquellas cuestionaban y que con sus formas culturales buscaban disputar.

Este trabajo forma parte de una investigación más amplia que buscó conectar las ideas y las prácticas de la izquierda anarquista, socialista y comunista en torno al "tiempo libre" de clases y sectores populares, que buscaban crear una cultura alternativa a las formas culturales del sistema vigente. ${ }^{6}$ Ese proceso no fue lineal y hacia 1935 se comenzó a visualizar cambios en las izquierdas en relación a la cultura popular y sus propuestas, acortándose las distancias entre ambas. Quienes primero comenzaron este acercamiento fueron los comunistas. Ese cambio puede ser explicable en modificaciones sociales y culturales, así como en la coyuntura económica y política abierta desde entonces. ${ }^{7}$

La importancia del tema reside en la relevancia de analizar, explicar y comprender los comportamientos sociales de la población trabajadora, las permanencias y los cambios, habida cuenta que la historiografía sobre el movimiento obrero ha estado más preocupada por estudiar las formas de protesta y organización y las ideologías.

\footnotetext{
${ }^{5}$ La participación femenina en el medio sindical -y las limitaciones impuestas a través de la doble jornada a las mujeres- ha sido abordada por Graciela Sapriza en varios textos: Los caminos de una ilusión. 1913 Huelga de mujeres en Juan Lacaze, Montevideo, Fin de Siglo, 1993, y en Hilamos una historia. La memoria sindical desde las mujeres, Montevideo, CIEDUR, 1989, pp.3-57; Javier Taks explora el proceso de trabajo femenino en la industria frigorífica en Fray Bentos y la participación gremial de las mujeres: "La clase trabajadora y la obrera del Anglo" en Revista Encuentros, Montevideo, No6, 1999. Estudiando la revista comunista Nosotras hacia 1946 Ana Laura de Giorgi destaca el análisis de las comunistas sobre la situación de la mujer obrera, denunciando la doble jornada: "Entre la lucha contra la carestía y por los derechos de la mujer. Las comunistas uruguayas durante la segunda mitad del siglo XX (1942-1973) en Adriana Valobra, Mercedes Yusta (eds), Queridas camaradas. Historias iberoamericanas de mujeres comunistas, Buenos Aires, Miño y Dávila Editores, 2017, pp.215-234. Para el tramo posterior a la segunda guerra mundial, la gremialista textil María Julia Alcoba ofrece un rico testimonio sobre la vida, trabajo y gremialismo en un barrio obrero Cerro (Montevideo): Las mijeres ¿̇donde estaban?, Montevideo, Ediciones Primero de Mayo, 2014. La ácrata Juana Rouco Buela, en su autobiografía Historia de un ideal vivido por una mujer (Buenos Aires, 1964), teniendo un destacado papel militante en varias ciudades del Rio de la Plata en gran parte del siglo XX, cuenta críticamente como los varones anarquistas relegaban a las mujeres en el protagonismo en las luchas. Para un tramo anterior (1870-1890) la investigación de Yamandú González Sierra planteó discusiones entre católicos, liberales e "internacionalistas" anarquistas sobre los papeles sociales femeninos, propuestas para la "cuestión femenina" y las "transgresiones" femeninas, así como la discusión sobre el "trabajo productivo" de la mujer con la pregunta que da título al libro ¿deshonra o virtud?: Del hogar a la fábrica ¿deshonra o virtud?, Montevideo, Nordan Comunidad, 1994.

${ }^{6}$ Rodolfo Porrini, "Izquierda uruguaya y culturas obreras en el 'tiempo libre': Montevideo (1920-1950)", Tesis de Doctorado, UBA, 2012, inédita, 355 pp y Anexos pp.40.

7 Este cambio estuvo ambientado por la atenuación de las prácticas anti-sistema, la nacionalización y renovación de la clase obrera y nuevas camadas militantes en sus integraciones; también por las luchas comunes, antidictatorial en lo interno y antifascista a nivel mundial, y el efecto de la política de Frente Popular impulsado por la Internacional Comunista.
} 
En este texto me posiciono en el debate sobre el carácter contracultural o alternativo de las propuestas de izquierdas, conviniendo como más acertado este último. ${ }^{8}$ El nivel de la intención y el sentido contracultural o de autónomo es visto por algunos como una apuesta profunda y enfrentada al sistema establecido, y tal vez estuviera presente en algún momento. El planteo de una cultura alternativa da cuenta de una realidad estructural y social más permanente, construida desde los trabajadores en su condición subalterna y explotada, y en su capacidad de ofrecer formas particulares de ver el mundo y vivir en él, incluso de rechazarlo y luchar por uno nuevo. En la construcción de ese sentido alternativo de lo cultural y el tiempo libre resulta importante la intervención y las acciones desplegadas por las izquierdas para interpretar e intentar cambiar el mundo capitalista.

Este texto se inscribe en una perspectiva historiográfica que considera relevante la conceptualización de clase y cultura trabajadora, diferente del estructuralismo y economicismo. ${ }^{9}$ Asume las culturas desde un enfoque amplio y que considera sus conexiones y tensiones (obrera, popular, militante o de izquierdas) que se nutre de ideas e investigaciones clásicas pero renovadoras, abrevando en trabajos de Edward P. Thompson, Richard Hoggart y Eric Hobsbawm. ${ }^{10}$ Asimismo, se ha nutrido de investigaciones en la región que han enfocado el mundo del trabajo, las izquierdas y sus vínculos, considerando en algunos casos las culturas obreras y en el "tiempo libre". Son los casos de Lobato al estudiar la comunidad obrera de Berisso, Suriano al examinar la cultura y política anarquista en Buenos Aires, y Camarero al enfocar aspectos de la relación entre los comunistas y la cultura obrera bonaerense, en adultos, niños e inmigrantes, en centros barriales y experiencias deportivas, y el impacto de nuevas formas de ocio; en Brasil, Batalha analizando el proceso de formación de una cultura asociativa tendiente hacia una cultura de clase, interrumpido a partir de 1930; en tanto Fortes y Fontes analizando impactos migratorios externos e internos, entre otros aspectos, en barrios y comunidades obreras (Porto Alegre, Sao Miguel Paulista). ${ }^{11}$ En los últimos años, la temática ha cobrado cierto interés en Argentina, Brasil y Chile, aunque aún quedan amplias zonas para la indagatoria. Como ejemplos, en Argentina existen trabajos referidos a las "masas" y el "tiempo libre", a redes populistas barriales en el primer peronismo, y el asociacionismo obrero y popular en Mar del Plata; en Chile, sobre la relación entre vida barrial, política y gremial de textiles y metalúrgicos en una comuna de Santiago de Chile, y el uso paternalista del deporte en la creación del "obrero soñado" en la región carbonífera; en Brasil, textos que estudian los vínculos entre trabajadores, asociaciones y mutualismo en diversas ciudades

\footnotetext{
8 Suriano criticó el uso del concepto "contracultural" proponiendo el carácter "alternativo" de la cultura anarquista. Juan Suriano, Anarquistas. Cultura y política libertaria en Buenos Aires 1890-1910, Buenos Aires, Manantial, 2001, p.27. Eva Golluscio y otros sostienen que el concepto de cultura "alternativa" o "marginal" podría sugerir cierto paralelismo entre esta cultura y la hegemónica, no dando enteramente cuenta de lo crítico y proposicional del anarquismo, tomando "más propiamente una forma de contracultura": Jean Andreu, Maurice Fraysse, Eva Golluscio de Montoya, "Introducción", en Anarkos. Literaturas libertarias de América del Sur 1900, Buenos Aires, Corregidor, 1990, p.5.

9 Siguiendo a Thompson, entiendo la clase como un proceso histórico que reúne un conjunto de aspectos "dispares y aparentemente desconectados" entre la "materia prima de la experiencia" y la "conciencia". La experiencia de clase se encuentra determinada por las relaciones de producción, y la conciencia es el modo en que se expresan esas experiencias a nivel de lo cultural, a través de "tradiciones, sistemas de valores, ideas y formas institucionales". Edward P. Thompson, La formación de la clase obrera en Inglaterra, Crítica, Barcelona, 1989 [1963], pp.XIII-XIV. El desarrollo de un estado de la cuestión y el análisis de los referentes teóricos sobre cultura obrera y tiempo libre ha sido abordado en la mencionada tesis de doctorado de Rodolfo Porrini, op.cit., pp.12-30.

10 Thompson, op.cit.; Thompson, Costumbres en común, Barcelona, Crítica, 1995, Richard Hoggart, La cultura obrera en la sociedad de masas, Grijalbo, México, 1990 [1957]; Eric Hobsbawm, El mundo del trabajo, Crítica, Barcelona, 1987.

11 Mirta Lobato, La vida en las fábricas, Prometeo Libros/Entrepasados, Buenos Aires, 2001; Hernán Camarero, A la conquista de la clase obrera, Siglo Veintiuno/Editora Iberoamericana, Buenos Aires, 2007; Alexandre Fortes, Nos do Quarto Distrito, Garamond, Rio de Janeiro, 2004; Paulo Fontes, Um Nordeste em Sâo Paulo, FGV Editora, Rio de Janeiro, 2008; Claudio H.M. Batalha, "Cultura associativa no Rio de Janeiro da Primeira República", en Claudio H.M. Batalha, Fernando Teixeira da Silva, Alexandre Fortes, Culturas de classe. Identidade e diversidade na formaçao do operariado, Campinas, Editora da Unicamp, 2004, pp.95119 . 
brasileñas hasta las primeras décadas del siglo XX, y uno que incluye el análisis de la vida cotidiana de los obreros del carbón en Rio Grande do Sul.12

Del punto de vista metodológico este artículo se ha basado en un análisis bibliográfico referido a la temática y en el examen cuidadoso y contrastación de diversas fuentes, principalmente la prensa de las tres tradiciones y grupos de izquierda considerados y de gremios por ellos orientados, literatura, testimonios éditos y entrevistas orales. La prensa ha permitido reconstruir en gran medida las variaciones en las ideas y análisis de las izquierdas sobre el "tiempo libre" de las clases populares y trabajadoras, de sus propuestas y prácticas. Los testimonios -y una obra literaria- han permitido contrastar algunos de los discursos más comunes, permitiendo percibir tensiones y otras dimensiones no presentes en las fuentes éditas y la prensa oficial u oficiosa de los respectivos grupos.

\section{Las veladas culturales y el "tiempo libre". Miradas y propuestas desde las izquierdas}

Hacia 1919-1920 Montevideo era una ciudad tensada entre diferentes fuerzas y opciones. Se vivía en la "república conservadora" con los sectores menos liberales en el Estado. Por su parte, las sociedades de resistencia, la anarquista Federación Obrera Regional Uruguaya (FORU) y la izquierda articulada en el Partido Socialista se rearmaban en un contexto de dura conflictividad, en la que se aprestaron todos a luchar por sus derechos y reivindicaciones. Junto a la lucha, después de la jornada laboral los gremios ofrecían jornadas nocturnas para que sus miembros se capacitaran, se formaran políticamente y tuvieran momentos de "expansión".

Un obrero militante tenía la opción -y la obligación- de instruirse y formarse -"iluminarse”-, convocado por los gremios y organizaciones de izquierda, desde los oradores, la prensa, y más adelante desde la radio. En el caso de las obreras militantes esta práctica se veía acotada a las funciones que además desempeñaban en sus hogares -imperantes tanto en la sociedad como en las izquierdas, salvo casos de destaque personal específicos de dirigentas gremiales o políticas. ${ }^{13}$. En su estudio sobre la cultura anarquista y aspectos del tiempo libre en Buenos Aires hacia 1890-1910 Juan Suriano ha reflexionado sobre el anarquismo, la atracción y participación de mujeres en las veladas y algunas contradicciones en torno a la familia y roles de la mujer en el hogar y como madre. Ha sostenido que los anarquistas "realizaron denodados esfuerzos" en atraer a las mujeres a la militancia, el espacio del

\footnotetext{
12 Diego P. Roldán, La invención de las masas. Ciudad, corporalidades y culturas. Rosario, 1910-1945, Universidad Nacional de la Plata, La Plata, 2012, Nicolás Quiroga, "Sincronías peronistas. Redes populistas a ras de suelo durante el primer peronismo", en Nuevo Mundo Mundos Nuevos, 2013, https://nuevomundo.revues.org/64851; Agustín Nieto, "Vida asociativa en una aldea peronista al ras del suelo. Activismo obrero y popular en Mar del Plata, 1943-1955", en Páginas, Año 7, No14, Rosario, 2015, pp.41-61; Sebastián Leiva Flores, Vida y trabajo de la clase obrera chilena. Los trabajadores textiles y metalúrgicos entre las décadas de 1930 y 1960, Tesis de Doctorado, Universidad de Santiago de Chile, 2017; Oscar Peñafiel Aranchibia, "Cuerpos fuertes, conciencias dóciles. La construcción del obrero soñado a través del deporte en la cuenca carbonífera. 1920-1950", en Enzo Videla Bravo, Hernán Venegas Valdebenito y Milton Godoy Orellana (editores), El orden fabril, Valparaíso, América en Movimiento, 2016, pp. 167-189; Marcelo Mac Cord, Claudio H.M. Batalha (organizadores), Organizar e proteger. Trabalhadores, associaçôes e mutualismo no Brasil (séculos XIX e XX), Campinas, SP, Editora da Unicamp, 2014; Clarice Gontarski Speranza, Cavando direitos. As leis trabalhistas e os conflitos entre os mineiros de carvâo e seus patrôs no Rio Grande do Sul (1940-1954), Sâo Leopoldo: Oikos, Porto Alegre: Anpuh-RS, 2014, pp.45-85.

13 En el caso montevideano, Sapriza estudia algunas de estas destacadas figuras femeninas: las anarquistas Juana Rouco Buela (española) y María Collazo, la socialista Paulina Luisi (primera médica en Uruguay), la comunista Julia Arévalo (primera Senadora en América): Graciela Sapriza, Memorias de rebeldía. Siete historias de vida, Montevideo, Puntosur Editores, 1988. Estas mujeres hacían frente a un contexto fuertemente patriarcal, dominado por ideas y prácticas que dificultaban su militancia, estudios y su misma vida personal. En el caso uruguayo, entre las primeras manifestaciones más o menos fuertes de feminismo y lucha de mujeres en las primeras décadas del siglo XX -a través de grupos, periódicos, líderes y militantes potentes-, y un resurgimiento tímido en el decenio de 1980, existió un extenso periodo de escasa visualización y potencia de ese tipo de movimientos y expresiones feministas, especialmente en los espacios públicos.
} 
"círculo", las conferencias y especialmente las veladas para su incorporación activa. Analizando los balances de fiestas y veladas descubre una presencia femenina importante pero menor a las de los hombres -un tercio aproximadamente- preguntándose si concurrían atraídas por el ideal libertario o acompañando a sus esposos, padres o hermanos. ${ }^{14}$

Los espacios en que los militantes de izquierda se alimentaban política y culturalmente y desarrollaban su sociabilidad eran los ateneos y centros de estudio anarquistas, las escuelas comunistas, los seccionales, centros y bibliotecas socialistas. Las juventudes organizaban "cursos de capacitación" como la Juventud Socialista de Montevideo en los años treinta, y las Juventudes Libertarias en los cuarenta. Las "universidades populares", integradas por gente de izquierda, pero de composición ideológica amplia, buscaron brindar a las clases populares conocimientos prácticos para ingresar al mundo del trabajo y "elevar" su educación.

Para realizar las veladas, recordaciones, actos y conferencias -que combinaban acción política, prácticas artísticas, formativas y lúdicas- se utilizaba los locales de ateneos y círculos y frecuentemente teatros y cines comerciales. Se incentivaba la lectura desde las bibliotecas, ateneos y escuelas, a nivel individual y como "lecturas comentadas" en grupo. Los periódicos y las editoriales promovían determinadas lecturas, comentaban libros para leer e "iluminarse", proponían un "plan" -"lecturas recomendadas"- apostando a formar lectores críticos. ${ }^{15}$

\section{Veladas culturales y festivales}

Las izquierdas anarquista, socialista y comunista contemplaron en el periodo diversas formas de educación y de formación en un amplio sentido -moral, intelectual, político e ideológico-, así como de "expansión cultural", sociabilidad y camaradería. Entre las expresiones que combinaban estos aspectos se hallaban las veladas. Ellas constituían una representación simbólica cargada de rituales, signos de rebeldía, sonidos y mensajes (himnos, cánticos, músicas, consignas) que constituían factores religantes del colectivo. Se exhibían elementos visuales (pinturas, grabados, banderas, decorados, figuras de los mártires, héroes y "fundadores" de las respectivas ideologías radicales). Eran ámbitos de expresión de lenguajes de clase, de composición heterogénea -obrera y obrero, migrante europea y criolla- que buscaban una lengua común expuesta en sus discursos, en la forma de referirse entre sí (cofrades, camaradas, compañeros), a los trabajadores, intelectuales, artistas y artesanos participantes en la fiesta. Además, en esa noche particular de velada se producía algo difícil de definir: ¿se daba una comunidad de acción con los camaradas de lucha? ¿se desplegaba un sentimiento de clase? ¿o la búsqueda de la elevación "cultural"? ¿'se buscaba encontrar amigos y afectos, entretenerse y pasar el tiempo? ¿o tal vez todas estas dimensiones juntas en esta experiencia social y cultural, como era la velada?

Una meta no siempre declarada pero presente en los años 20 y 30 era el intento de captar a los trabajadores para esa instancia cultural alternativa, alejándolos de los "vicios sociales" y ambientes

\footnotetext{
14 Juan Suriano, Anarquistas. Cultura y política libertaria en Buenos Aires 1890-1910, Buenos Aires, Manantial, 2001, pp.147-153: "La mujer y la familia". En este breve y muy agudo análisis, también destaca que el discurso anarquista sobre la mujer estaba cruzado por incertidumbres y contradicciones. Estas iban desde sus reflexiones sobre la inferioridad a que eran sometidas por la "doble explotación por su carácter de explotada y de mujer", la discusión sobre su supuesta "debilidad", o las tareas asignadas al hogar y como madre. Refirió también al fuerte debate que se suscitó entre ácratas en torno a La Voz de la Mujer surgido en 1896, "periódico libertario hecho exclusivamente por mujeres y para mujeres" con cuyas duras críticas al "género masculino en general" despertó reacciones adversas entre los libertarios varones, desautorizándolas "por insensatas e inmorales": Suriano, Anarquistas, op.cit., p.150.

15 Barrancos analiza estas prácticas en los anarquistas argentinos en un periodo cercano a nuestro estudio, estudiando los textos comentados, su selección, y la forma de tales prácticas. Dora Barrancos, "Lecturas comentadas. Un dispositivo para la formación de la conciencia contestataria. 1914-1930”, en Boletín XVI, CEIL, CONICET, diciembre 1987. Destaca también en algunos casos el papel del padre en "lecturas dirigidas" en relación a miembros femeninos de la familia, y el fuerte empuje de "conversaciones familiares" a comienzos del siglo XX.
} 
considerados nocivos que se interponían en su proceso de concientización y participación en el movimiento revolucionario, o simplemente de experimentar valores y prácticas diferentes a los de la sociedad burguesa.

Además de esto, se presentaban objetivos concretos (recaudar fondos para la prensa sindical o partidaria, los comités pro presos, los conflictos sindicales) y otras manifestaciones de solidaridad con la clase obrera nacional y luchas de carácter internacionalista. Y también, como ha señalado Suriano para el caso porteño, la posibilidad de atraer militantes y asistentes, hombres, mujeres y niños.

Junto a las actividades al aire libre, en los ámbitos cerrados se destacaron las "veladas culturales" como prácticas comunes de las izquierdas que llegaron hasta comienzos de los años cincuenta. Según primaran unas u otras formas se denominaban artísticas, teatrales, artístico-musicales, literario-musicales, cinematográficas, culturales o simplemente veladas. Se realizaban en espacios cerrados -salas de teatros y cines, salones sindicales o partidarios- y con una variedad de géneros y actividades. Sus formas fueron modificándose a lo largo del tiempo y las mismas "veladas" llegaron a resultar raras y casi a desaparecer al fin del periodo.

Así como otras expresiones culturales -ateneos y bibliotecas-, las veladas estaban presentes en la sociedad montevideana, eran compartidas con otros sectores sociales, políticos y culturales (inmigrantes, liberales, católicos). Se puede presumir cierta contigüidad entre las veladas de las izquierdas y las de otros sectores ideológicos, así como diferencias entre ellas. ${ }^{16}$ Siendo una forma originaria de la cultura de elite, pudo ser reapropiada por las izquierdas y algunos gremios, dotándola de otros sentidos.

Puede afirmarse así que las veladas fueron una de las manifestaciones culturales y del tiempo libre más significativas y comunes en las décadas de 1920 y 1930. Se produjeron entre los anarquistas, en menor medida en socialistas y comunistas que adoptaron otras formas -festivales, bailes- o las combinaron con otras expresiones. En general fueron usadas por estas tres corrientes, así como por sindicatos y ateneos en los que aquellas influían.

¿Cómo lograban atraer a los trabajadores y trabajadoras? Las veladas eran espacios de sociabilidad, fraternidad y "vida sana", vehículos de propaganda ideológica, medios para obtener fondos para distintas causas justas, la solidaridad con huelguistas o con los republicanos españoles, que podían tocar la fibra de los trabajadores y sus familias, acercar militantes o simpatizantes a la actividad. Las actuaciones en vivo eran un elemento de atracción, aunque dependiendo de la calidad de los actores, podían resultar también factores de rechazo o simple aburrimiento. Aunque ¿qué sabemos de cómo vivían esas horas de compartir con los compañeros de causa?

Las veladas implicaban una variada gama de iniciativas preparatorias que iban desde la organización y ensayos de los conjuntos -corales, filodramáticos- o solistas que actuaban en vivo, la confección de propaganda, el arriendo y acondicionamiento de los locales, la venta de entradas y de rifas, y los trámites ante los organismos municipales; y la engorrosa tarea de "rendir cuentas" en los meticulosos "balances" de cada actividad de este tipo, publicados luego en la prensa partidaria o gremial.

Entre los múltiples géneros artísticos que contemplaba una velada, se incluían representaciones teatrales, la ejecución de música, canto, recitado de poesías, bailes y danzas, la proyección de filmes, y conferencias o alocuciones orales. Las veladas anarquistas, en el entorno de los años veinte eran muy

\footnotetext{
16 Los ateneos tuvieron importante implantación en regiones europeas como en España desde mediados del siglo XIX: Navarro Navarro, "El papel de los ateneos en la cultura y la sociabilidad libertarias (1931-1939): algunas reflexiones", Cercles, 8, Barcelona, 2005, pp. 64-104. Fueron especialmente valorados en Uruguay, existiendo el Ateneo de Montevideo -con intelectuales liberales y socialistas- y otros en ciudades del interior, los cuales no tenían un carácter obrero ni específicamente de izquierda. Por ejemplo, el Ateneo Paysandú organizó un "gran acto cultural de carácter americanista", participando ateneos de Montevideo, Salto, Rivera, Ateneo Popular y la Biblioteca Gabriela Mistral, en El Sol, Montevideo, $1^{\text {a }}$ semana abril de 1936, p. 5 .
} 
completas y tal vez también extendidas en su duración, quizá tres o cuatro horas. La música provenía de un modelo de "alta cultura" y contenía sinfonías -que acompañaban las imágenes del cine mudo, y también en distintos periodos canciones y bailes de las comunidades extranjeras y étnicas más presentes en el Montevideo de entonces, italianos y españoles, más aún napolitanos y gallegos entre aquellos, y luego judíos y eslavos. Un relevamiento específico en clave de género podría determinar -aún con la limitante de la información de las fuentes- en cuáles de los tipos de actividades había diferenciación en tal sentido, por ejemplo, la conformación por sexo de los cuadros filodramáticos, o la autoría de las diversas actuaciones como solistas o en grupos. Sin ser un porcentaje comprobado, es muy probable que el momento de la oratoria o conferencia fuera "un compañero" quien tomara la palabra -aunque las hubo mujeres como Juana Buela, María Collazo y Julia Arévalo-, actrices en las representaciones teatrales, así como en poesía y recitado fueran mayoría niñas y muchachas. En algunas oportunidades una forma de incentivar la ida de mujeres a veladas y festivales o bailes era diferenciar el precio de las entradas, con uno menor para mujeres y niños, y en casos de festivales y bailes las "damas" ingresaban gratis. Esta era una práctica frecuente además en ambientes sindicales y de izquierdas, también en los pic-nics, y en general en la sociedad montevideana, aunque no en todos los eventos. ${ }^{17}$

Las representaciones teatrales fueron muy importantes durante casi todo el periodo, prevaleciendo en los veinte y parte de los treinta, comenzando desde allí una disminución de su inclusión en estos eventos sociales. Las mismas eran desarrolladas por los "cuadros dramáticos" o "filodramáticos". Entre ellos estaban el socialista y luego comunista "Sol de Mayo" (desde 1919), el comunista "Claridad" (1928), el socialista "Florencio Sánchez" (1936) o el cuadro dramático de las juventudes libertarias "Tierra y Libertad" (1939). Las obras representadas tuvieron una impronta realista usando el teatro identificado con un teatro "social y revolucionario", también exhibiendo otras con menor fundamento doctrinario e interés artístico, cercanas al grotesco o el vodevil y a las comedias "reideras". ${ }^{18}$ Cubrían géneros que iban desde "dramas sociales" o "de tesis", hasta sainetes y "comedias" más sencillas y livianas en su confección y contenidos. Ejemplo de estas últimas fue la "divertida comedia" en tres actos de F. Mertens "La familia de mi sastre" en una velada socialista de enero de 1920. Entre los autores predilectos -todos varones los mencionados- estaba el muy considerado por los ácratas Florencio Sánchez -y también por las demás corrientes ideológicas-, el libertario argentino Rodolfo González Pacheco -alguno de cuyos dramas se vendían en folletos, como en 1925 "Hermano Lobo y Natividad"-, y otros menos conocidos pero vinculados al ambiente socialista o al movimiento sindical, por ejemplo, entre los libertarios Conrado Rodríguez, cuya obra "Mi Primer Pleito" se editó como folleto en 1949. Entre los "foráneos" se ponían en escena textos del ruso Máximo Gorki como "La Madre".

La presencia del cine fue importante en casi todo el periodo, hasta volverse casi exclusiva en veladas y festivales gremiales y de izquierda en la década del cuarenta. Entre las preferidas estaban, como ya vimos, las películas "de crítica social" o "de crítica de guerra", las de humor crítico, en especial las de Carlitos Chaplin, las francesas (el realismo poético de Renoir), las del neorrealismo italiano, las "yanquis" críticas ("Viñas de ira" de John Ford), las soviéticas clásicas de Eisenstein como "Potemkin"

17 Un ejemplo, un "gran festival" bailable preparado por la Unión Femenina en marzo determina el precio de entradas de \$1 para varones y $\$ 0,50$ para damas: Diario Popular, Montevideo, 4/3/1947, p.2. Para Buenos Aires, Suriano sostiene que con el fin de atraer mujeres "se hacían los bailes, los frecuentes actos de declamación poética o las representaciones teatrales que, destinados a un público de ambos sexos, incorporaba a la mujer no tan solo como espectadora sino también como protagonista", aunque mencionaba que no halló una sola mujer entre los autores de las obras representadas: Suriano, Anarquistas ..., op.cit., pp.147-148.

18 Es llamativo que en 1928 el género "grotesco" representado en teatros comerciales recibiera buena crítica por la prensa comunista: “'STEFANO” Grotesco de Armando Discépolo llegó anoche a las 100 representaciones ... en el Teatro Cómico de Buenos Aires", destacando que "ha merecido junto con sus intérpretes, el aplauso caluroso del público" premiando así "la labor de Discépolo interesante y honesta": Justicia, Órgano del Partido Comunista, Montevideo, 6/6/1928, p.2. 
y las bélicas que aludían al papel de la URSS durante la Segunda Guerra. Así como en el teatro, en particular en los sindicatos y barrios populares, también se exhibían filmes melodramáticos y comedias argentinas como las protagonizadas por Luis Sandrini.

La parte discursiva -ideológica o política- era un componente importante en la mayoría de las veladas y festivales. La "palabra de un compañero" o "compañera", la conferencia de un especialista, o la oratoria de un sindicalista, era un momento especial, a veces breve, en el conjunto de la representación global de esa jornada. Ese era el tiempo y el espacio para un "mensaje" claro y quizá esperado sobre algún tema, fuera el Primero de Mayo, un "atropello policial" o el "carácter social de la tuberculosis".

Las veladas se realizaban en horarios nocturnos, comenzando no antes de las 20 y 30 y generalmente un poco más tarde, desde las 21. Los días de fin de semana eran los preferidos para su realización, en primer lugar, los sábados y luego los domingos y viernes. Su frecuencia varió, pues seguramente no era fácil la organización de actividades cada semana, llegando a haber veladas de carácter mensual en los meses de primavera y otoño. La cercanía del Primero de Mayo motivaba una concentración importante de actividades alusivas, y obviamente se producían varias "veladas" paralelas impulsadas por distintas organizaciones políticas, sindicales o culturales. La asistencia máxima dependía de los límites ofrecidos por la capacidad instalada de teatros y cines -entre 300 y 1.000 butacas-, o de los locales deportivos y partidarios a los que recurrían los organizadores, pero también se vinculaba a los atractivos prometidos o al compromiso contraído con quienes invitaban. De acuerdo a los "balances" en general la cifra de participantes variaba entre trecientos y los setecientos espectadores.

Menos perceptible al inicio fue la transformación de las veladas en los géneros que integraba y también en sus sentidos, así como existencia paralela de otras formas de sociabilidad y cultura festiva obrera y popular que emergieron a finales de los años veinte y se desarrollaron en las décadas posteriores. Esto corría paralelo a fuertes cambios culturales que vivía la sociedad montevideana, que trajeron el "imperio" de la radio y su masificación en los años 30, así como desde antes el cine y transformaciones en el teatro. Se fue modificando el lenguaje y variando la denominación de las "veladas", siendo cada vez más frecuentes desde los años cuarenta los "festivales", "fiestas" y "funciones" (de cine, de teatro o "a beneficio de"), hasta que aquellas desaparecieron en sus modalidades tales como existían desde principios del siglo XX.

Sus sentidos, objetivos y formas fueron trocando en otras modalidades de expresión, sociabilidad y cultura obreras.

\section{Las noches de veladas.}

Gabriel y Segundo habían sido invitados por Juliano a una "Gran Velada literario-musical", regalándole las entradas y el correspondiente Programa. El personaje de la novela Oficio de vivir, quien no era entonces un "militante" relata su primer acercamiento a una velada en el Centro Internacional. ${ }^{19}$ Gabriel recrea el ambiente libertario, mostrando a quien recién "llega" al mismo y refleja las inquietudes de un trabajador en problemas. El Centro anarquista podía volverse un lugar para hallar "compañeros" que le dieran una mano con el trabajo, el techo y aún el alimento. Al entrar reconoce un local amplio con sillas muy viejas y en algunos sectores largos bancos de madera, y como se permitía fumar "el local estaba lleno de humo y olía a sudor proletario". Como aún no comenzaba la velada Gabriel recorría con sus ojos el salón, encontrando "alegorías revolucionarias" e inscripciones que no comprendía ("Trabajo, Pan y Ciencia") y nombres escuchados por primera vez: Marx, Bakounine, Proudhon y Kropotkine. Como pasaba la hora y el programa no empezaba, demandó “¿Demorará la función”, a lo que respondió Segundo "Ma cuesto no é simplemente una funcione di teatro. Es un acti di solidaritá

${ }_{19}^{19}$ Manuel de Castro, Oficio de vivir, Ediciones Banda Oriental, Montevideo, 1959, p.144. 
obrera", explicando así el sentido diferente y alternativo del evento. El programa, ficticio, pero probablemente, muy parecido a la realidad, contemplaba la siguiente secuencia: Primera Parte. Apertura del Acto por el compañero Amílcar Miramar; Hijos del Pueblo por el Coro y Orfeón Literario; la pieza de Pietro Gori "10 de Mayo", la cual era representada por el cuadro Filodramático "Eliseo Reclús". Luego del Intervalo venía la Segunda Parte, iniciada con la ejecución de "Bandera Roja” a cargo del Coro y Orfeón Literario, "Canzione di Lavoratori" de Ada Negri, recitado de la Señorita Aida Signorini. Cerraba el acto el "compañero" Carlos Montalbán. En el relato de su experiencia Gabriel reconoció lo largo y aburrido del discurso de Miramar, frente a los más entretenidos cantos y representaciones incluida "la bella Signorini"- y el agitativo, cortante y más breve discurso final de Montalbán. ${ }^{20}$

¿Cómo saber qué atraía efectivamente a los centenares de asistentes -militantes y sus familias-a concurrir un sábado a la noche a la velada anarquista o socialista o a un festival comunista en vez de ir al boliche de barrio, el cine comercial o a un baile del centro de la ciudad? Esta pregunta valdría también para conocer la voluntad de mujeres, jóvenes y niños que allí concurrían, o que "eran llevados" por los "jefes de hogar". Una velada de origen gremial orientado por anarquistas propagandeada en el periódico de los sastres Despertar se realizó a comienzos de setiembre de 1918 "a beneficio de los padres del extinto compañero Pascual Lorenzo". ${ }^{21}$ Los fondos obtenidos se volcarían a los familiares directos del compañero fallecido, lo que mostraba el significado solidario de esta acción en un contexto en que aún no existía un sistema de seguridad social y jubilaciones en muchas de las actividades económicas, lo que volvía más necesario y fundamental el apoyo entre la "familia obrera". Además, en la velada se abría un mundo cultural tras los salones que contendrían música, canto, discursos revolucionarios, encuentros con amigos y amigas y desconocidos "compañeros" que abrazaban un fin común. Una primera parte de la velada -quizá la más "seria"-, se componía de una sinfonía por la orquesta "Heraldos de la Noche", una comedia dramática en dos actos -"La Quiebra" de Edmundo Bianchi-, una poesía, y una conferencia por la Sra. María Collazo, reconocida como una muy buena oradora y orientadora del periódico anarquista La Batalla, propenso en esos años a la revolución rusa en curso. La segunda parte tenía múltiples componentes: una sinfonía, macchiettas, tonadillas, canzonetas regionales, canzonetas napolitanas, una melodía napolitana por un tenor, y una tarantela bailada por niñas. Todo esto revelaba un tono inmigrante definido y posiblemente más divertido y vinculado a conocidas expresiones culturales e intereses de los asistentes. La tercera parte seguía en la misma línea con ese tipo de canciones y bailes, sumando una "danza pastoral de los Apeninos", y una presencia importante de "niñas" en casi todas las actuaciones. ${ }^{22}$ Finalizaba con la actuación de un cómico. El carácter familiar de la velada dado por la presencia de las y los infantes y el gran porcentaje de números musicales, los cómicos y los bailes "regionales", abonan en la idea de un público mayoritariamente extranjero y con integrantes de la familia de diversas edades. Asimismo, estaría evidenciando una significativa presencia femenina, al menos en la actuación de las jovencitas danzarinas y posiblemente la de sus madres, aunque sería importante poder relevar la presencia también en el público como ha realizado Suriano en el estudio ya mencionado. El elemento "ideológico" estaba bien contemplado con la eficaz y potente oradora anarquista María Collazo. El balance de la velada hecho por sus organizadores fue realmente positivo considerándolo "un éxito", pues el salón "de nuestro local fue chico para el público" que estuvo compuesto de compañeros del gremio y "libertarios -muy posiblemente aludiera a los varonescon sus respectivas familias". ${ }^{23} \mathrm{Da}$ una idea de los asistentes la venta de entradas, todas al mismo precio: se vendieron 341 , a $\$ 0,20$ centésimos.

Una velada comunista en marzo de 1923 en la Casa del Pueblo era sencilla, conteniendo tres elementos fundamentales, el discurso de un respetado dirigente del PC, la presencia de un coro, y la

\footnotetext{
20 Ibid., pp.146-148.

21 Despertar, Publicación de la Sociedad de Resistencia Obreros Sastres, Montevideo, agosto 1918, p.710.

22 Idem.

23 Ibid., octubre 1918, p.727.
} 
representación teatral de un conocido "cuadro artístico". Se realizaba teniendo como objetivo recaudar fondos para mantener la prensa partidaria, el diario Justicia. Se publicitaba así la actividad "Hablará Pintos, cantará el Coro Comunista y actuará el prestigioso cuadro SOL DE MAYO”. ${ }^{24}$ Esta otra al año siguiente se parecía más a las de los ácratas y socialistas, con un Programa más denso que contaba con nueve actuaciones: 1) sinfonía por la orquesta, 2) el "colosal suceso 'Patria y divisa", 3) palabras alusivas del dirigente partidario D. Martínez Catalina, 4) "Lengua de trapo", monólogo cómico por Homero Peyrot, 5) recitación poética por Alfredo Cáceres, 6) Alvaro Laureiro, 7) sinfonía por la orquesta, 8) recitación por Argelia Campistrous, 9) estreno de comedia en dos actos de F. Antonio Saldías "Los angelitos". Se advertía que "Los grupos infantiles comunistas tendrán libre entrada al salón” y de los precios diferenciados establecidos: Platea hombres $\$ 0.20$, señoras y señoritas $\$ 0.20$, entrada general $\$ 0.10 .25$

María Julia (Coca) Campistrous recordó su participación en la formación de los "cuadros artísticos" socialistas, que luego del congreso de 1921 devinieron en comunistas. Destacó las actuaciones de su hermana: "Argelia fue una de las personas que recitaba en todos los actos ... fue la que paseó e hizo conocer la figura de Rosa Luxemburgo, con el poema de Elías Castelnuovo, 'Rosa Roja', era un hermoso poema, divino ... iba a cualquier acto, pero si no recitaba 'Rosa Roja' no bajaba del escenario" [risa]. También recordó “nosotras también venimos de los 'cuadros artísticos' que hoy se llaman 'teatros independientes', ahí formamos, del [19]20 al 25 los cuadros artísticos, y nosotros hicimos 'M'ijo el Dotor', empezamos siempre haciendo las obras de [Florencio] Sánchez”. 26

Una actividad organizada por la Organización Juvenil Comunista adoptaba al parecer tempranamente una forma que sería muy común -y se integraría a las demás- en los años siguientes: el baile. A beneficio de la "Caja Central" de esta sección de jóvenes comunistas se anunció el "baile" en la Casa del Pueblo para el 4 de mayo de 1924 con la "orquesta Carrión". 27 A comienzos de los veinte las representaciones teatrales, actuaciones de cómicos, la música y los bailes "regionales" eran dominantes, en la atmósfera envolvente de los "himnos" revolucionarios compartidos por las izquierdas. A fines de esa década los comunistas desplegaron una intensa actividad cultural y en las veladas se pudo apreciar algunos cambios que serán significativos en el siguiente decenio, pues además de lo artístico-musical y la conferencia política incluyeron "bailes". Una velada anunciada para el sábado 4 de febrero de 1928 en el local del Club Vorovsky se presentaba como "velada, baile y conferencia". ${ }^{28}$ El sábado 19 de mayo y en el mismo sitio se realizaba una velada con el objetivo de promover y recaudar fondos "Pro Espartakiada de Moscú" a celebrarse ese año, alternativa a los Juegos Olímpicos de Amsterdam. La misma comprendía una representación por el Cuadro Artístico Claridad -el sainete "La Perra Vida"-, la trouppe Petit Oxford "por el maestro Garrido interpretando canciones populares", números de canto y un monólogo "de gran efecto cómico", un bazar-rifa, y finalmente el baile. En relación al baile se sostenía que "es lo que interesa a la gente joven y bailarina". ${ }^{29}$ Esto da pistas sobre la importancia de los jóvenes para los comunistas y su preocupación por atraerlos a la militancia. Desde entonces el recurso del "baile" fue permanente, y para sus actividades culturales y de recreación se usó el término "festival", "festival artístico" o "fiesta", aunque hasta fines de los treinta aún subsistían algunas "veladas".

En un total de diez actividades de este tipo relevadas -cuatro en 1928 y seis en 1930-, siete incluían "bailes" de algún tipo, y posiblemente en dos más también lo hubiera, salvo una "velada cinematográfica" que no lo incluyó. Otra característica que comienza a percibirse en las actividades

\footnotetext{
${ }^{24}$ Justicia, 22/3/1923, p.4.

25 Justicia, 6/6/1924.

26 Entrevista a María Julia Campistrous, realizada por Rodolfo Porrini, Montevideo, 27/4/1991.

27 Justicia, 2/5/1924.

28 Ibid., 4/2/1928.

${ }^{29}$ Ibid., $19 / 5 / 1928$.
} 
comunistas fue el uso cada vez más frecuente de las proyecciones de cine, lo que ocurría también en los eventos libertarios y socialistas.

Entre sus objetivos las veladas combinaban también la celebración de las efemérides proletarias internacionales y la reunión de solidaridades y recursos para las causas planteadas por la coyuntura mundial. Una velada organizada por el Socorro Rojo para denunciar la situación de los "presos de Polonia" el martes 5 de junio en el cine Lutecia, contenía música (sinfonías), recitado, bailes, cantos por el Coro Israelita, cine y casi al final unas "palabras sobre la organización del Socorro Rojo, por uno de sus miembros". En el comienzo y en el final se proyectaban películas, en la última parte el film soviético "Iván el terrible", acompañado de la "sinfonía" por la orquesta Poli Taranto, al ser cine mudo. ${ }^{30}$ El comentarista de Justicia señalaba que era "la creación cinematográfica más notable conocida" una de las raras producciones "que nos permiten vislumbrar el futuro prodigioso que espera al llamado séptimo arte".

Como se vio, otro de los móviles comunes perseguidos por las agrupaciones sindicales y de izquierda con la realización de este tipo de eventos era la obtención de fondos para subvencionar su prensa. El "Centro de Estudios Sociales del Paso del Molino" organizó una velada el 30 de abril de 1930 en el Teatro Apolo de la Villa del Cerro "a beneficio del Comité pro Prensa", además de conmemorar esa víspera el Primero de Mayo. ${ }^{31} \mathrm{El}$ mismo día, y aludiendo este último objetivo, una "gran velada socialista" se realizó en el barrio Aguada, en el American Cine en Sierra y Miguelete desde las 21 horas. La misma incluyó un extenso programa con la ejecución de "La Internacional", la película "El enemigo", "bailes clásicos" y canciones, así como parodias e imitaciones. La tercera parte terminaba con el himno revolucionario "Hijos del Pueblo", una audición de canto acompañada de piano, una de guitarra y "el pericón nacional"; y otras obras ejecutadas por el cuarteto clásico "Montevideo" de la "Agrupación de Música de Cámara "Montevideo". ${ }^{32}$ Se nota en esta velada socialista la incorporación del cine, y el reconocimiento de la tradición musical "patria" con el pericón, además de expresiones de la "alta cultura".

Desde el ámbito gremial, el "Comité pro Semana Inglesa" de los empleados de comercio organizó una velada en agosto de 1930. Es posible advertir también en esta velada un tono más típico de la "alta cultura", justamente en un gremio con influencia socialista, además de realizar la conferencia reivindicativa específica. La misma constaba del film "Resurrección” basado en una obra de Tolstoi, y un "Acto de Concierto". En la tercera sección se ejecutaron los "discos selectos" Khowantchina (Opera rusa) e Invitación al vals de Weber, seguida de una disertación sobre el tema 'Semana Inglesa' por la educacionista Señorita Adela Barbarita Colombo. La velada culminaba con la proyección de "Cintas sonoras de dibujos animados", mostrando así interés por motivar y acercar a los niños. ${ }^{33}$

Los primeros años de la década del treinta y más aún luego del golpe de Estado conservador de marzo de 1933, la actividad sindical y de izquierdas se vio afectada por la represión estatal. Esto provocó una disminución drástica de la frecuencia de la movilización y de las veladas culturales. Una de ellas fue organizada por el Comité pro presos de la FORU, en beneficio del mismo comité y la FORU. Esta "función cinematográfica", se realizó en la noche del domingo 30 de abril de 1933 en el Cine Agraciada, con recitados de la "compañera Blanca Burgueño", de trayectoria en la radio, una conferencia sobre los presos Kerbis y Cisneros, y los filmes "El patrón del barco" por Lupino Lane y “"Sensacional! La caída de San Petersburgo". ${ }^{34}$ El viernes 19 de mayo, una nueva actividad preparaba la Agrupación Progreso en el Cine Teatro Miramar del Cerro. La sinfonía acompañaba el film que era un

\footnotetext{
${ }^{30}$ Justicia, 4/6/1928. Se trataba de una película previa a la de Sergei Eisenstein, cuya primera parte es de 1944.

31 Unión Sindical, Órgano de la Unión Sindical Uruguaya, Montevideo, 1\%/5/1930, p.3.

32 El Sol, Órgano del Partido Socialista, Montevideo, 30/4/1930, p.2.

33 Ibid., 31/8/1930, p.1.

34 Solidaridad, Órgano de la Federación Obrera Regional Uruguaya, Montevideo, 1\%/5/1933, p.3.
} 
"estreno de la obra de Eugenio Sué 'El judío errante", un recital poético por Blanca Burgueño, un concierto de violín y la segunda parte de "El judío errante". 35

\section{Tiempos de cambios}

A mediados de los años treinta la reactivación económica y en lo político el antifascismo y la lucha antidictatorial contra el régimen dictatorial (1933-1938), ambientaron un marco propicio a la reorganización sindical y la acción de los grupos de izquierda. Así crecieron sus actividades culturales, entre ellas veladas y festivales. Mientras en los comunistas comenzó a verse un cambio significativo en sus posiciones sobre la cultura popular y su acercamiento a ésta, las otras corrientes mantuvieron sus distancias y críticas de aquella. Los comunistas continuaron haciendo festivales y veladas, donde los bailes adquirían una presencia cada vez mayor, en tanto era más raro encontrarlas en las actividades de ácratas y socialistas, salvo en los paseos campestres. Fue común a todos ellos el creciente uso del cine tanto el político-social como el "comercial"-, y el lento abandono del teatro y otras artes escénicas típicas de los años veinte. Con el comienzo de la Segunda Guerra Mundial, los libertarios definieron una posición contraria a la misma y en sus veladas exhibieron muchas veces películas pacifistas francesas por lo general-, que denunciaban las guerras, tanto la de 1914-1918 como la iniciada en 1939. En tanto los comunistas, además de Chaplin, fueron apasionados promotores del cine soviético, tanto el que mostraba las ventajas de la vida en la URSS, como el que registraba la heroicidad del pueblo soviético durante la ocupación alemana y la resistencia.

En el campo comunista desde 1936 se notó un importante movimiento cultural en sus sindicatos, "clubes idiomáticos" vinculados a comunidades de origen étnico, asociaciones de apoyo a los republicanos españoles, así como las instancias propias del partido. La sección Pocitos de la Federación Obrera Tranviaria -un sindicato que salía entonces de una gran huelga victoriosa- organizó en agosto de 1936 un "festival y baile" en el local de la Sociedad Agrícola Italiana, ubicada en 8 de Octubre y Propios (Unión). La misma contó con una conferencia del Dr. Prunell, un drama en tres actos ("Los parásitos"), y un fenómeno de aparición esporádica en este tipo de eventos, la actuación del payador Pedro Medina. Culminaba con un "baile familiar", anunciando que se prolongaría hasta las 5 de la mañana. Tratándose de un gremio con un gran componente masculino, es de suponer la presencia de esposas, novias o hermanas en el mismo.36 Por las mismas fechas, los clubes "idiomáticos" vinculados al comunismo (Club Cultural Winchesky, Club Obrero Húngaro, Clubes Ucranianos) realizaban en el "Victoria Hall" un festival artístico y baile, actuando los "aplaudidos Artistas Nacionales". ${ }^{37}$ Un festival de la comunista Confederación General del Trabajo del Uruguay (CGTU) incluía actuaciones de un cómico, los coros Lituano y Húngaro, recitados de un "cantor nacional", diversas "danzas guerreras" ucranianas y el baile hasta las 24 horas. ${ }^{38}$

A nivel partidario, el Comité Femenino del PC organizó en junio de 1938 un "Te danzante" con rifa y buffet. Ese comité y el de Justicia realizaron una kermesse, con bazar-rifa y buffet en el local del Ateneo Popular, logrando "una nutrida concurrencia juvenil". En la convocatoria se invitaba a "Las compañeras que lo deseen pueden hacer para el Bazar Rifa, alguna labor o algún postre, que serán muy bien aceptados", proponiendo a las mujeres la ejecución de tareas consideradas femeninas o propias de la mujer. ${ }^{39}$ Teniendo en cuenta estas nociones, sería pertinente indagar en cómo operaba la división sexual del trabajo en las tareas asignadas en el proceso de organización y de ejecución de las veladas.

\footnotetext{
35 Solidaridad, ibidem, p.4.

36 Justicia, 21/8/1936, p.3.

37 Ibid., $11 / 9 / 1936$.

38 Ibid., 25/9/1936. La incorporación del cantor nacional o criollo y el payador, podría tener relación con la tendencia a la

"nacionalización" de las izquierdas, al menos de socialistas y comunistas en estos años, y también de los anarquistas.

${ }^{39}$ Ibid., 1\%/7/1938, p.3; Ibid., 10/6/1938, p.3.
} 
En diciembre la comunista Editorial Unidad organizó en el salón del Banco Israelita un festival con "varieté" y baile.40 "Jóvenes Amigos de España Leal" realizaron en diciembre de 1938 una "Velada de cine" con el "formidable film soviético "Noches de San Petersburgo". ${ }^{41}$ De doce "festivales" comunistas realizados entre 1936 y 1938, nueve incluyeron bailes, siendo sólo uno exclusivamente cinematográfico.

Las veladas y festivales socialistas y anarquistas de fines de los treinta conservaban en general las características más típicas de las veladas que se vio desde los años veinte, e iban incorporando elementos no tan comunes como el "canto criollo" y usando más a menudo el cine. Una velada del Comité Pro Presos del Sindicato de Panaderos realizó el 24 de enero de 1936 una velada al "viejo estilo". Comenzó con la ejecución de himnos -entre ellos La Marsellesa- conferencias, obras teatrales por el cuadro artístico "Florencio Sánchez", un concierto de violín con música clásica, y las "canciones criollas" del cantor Benito Ovalle. ${ }^{42}$ La conferencia inicial versó sobre la "Solidaridad con los Presos Sociales", acorde con el objeto principal. Si bien el gremio de panaderos era anarquista, el dirigente y poeta socialista Roberto Ibáñez fue invitado a participar con una conferencia sobre "El Arte Teatral como medio de Cultura Popular", mostrando cercanías entre ambas corrientes, como la que llevaban en el Ateneo Popular. El Ateneo y Universidad Popular de Peñarol -con influencia socialista- realizó una "velada teatral" en el Club Artesano de aquel barrio. ${ }^{43}$ También se puede reconocer el uso cada más vez más frecuente del cinematógrafo: un evento del PS en el Cine Cervantes contó con "una sinfonía tonta de Mickey", una "importante película" ("A nosotros la libertad"), y en la segunda sección "El hombre que reclamó su cabeza". ${ }^{44}$ Los socialistas también apoyaron la velada de cine que organizó el Comité de Ayuda a los Tranviarios de la sección $18^{a}$ y $24^{a}$ Sección, en el Cine Savoy Palace de Pocitos, con dos filmes bastante convencionales de acuerdo a sus títulos: "Mundos Individuales" y "Valientes Submarinos (De Espinaca) El último saludo". 45

Durante la guerra civil española fue importante la campaña de solidaridad con la causa republicana y la revolución española, desde las izquierdas y sindicatos, así como de sectores de izquierda o antifranquistas de los partidos Colorado y Nacional. Se producía así una amplia actividad en la que impulsaron reuniones y actos para reunir fondos para los republicanos y exponer afiches propagandísticos. La Juventud Socialista de Montevideo organizó una "exposición de affiches españoles" en la Casa del Pueblo en marzo de 1937.46 El anarco-sindicalista Sindicato de Artes Gráficas realizó a fines de 1937 una exposición de afiches de la C.N.T. y la F.A.I. (Confederación Nacional del Trabajo, Federación Anarquista Ibérica) en los salones del Ateneo de Montevideo. ${ }^{47}$ El sábado 29 de enero de 1938 en una velada, el Cuadro artístico Florencio Sánchez puso en escena "El Deportao", del militante gráfico José M. Ferreiro "en un acto, de crítica social y de costumbres criollas", y la comedia satírica de Ángel Gómez Giz "Pamperada". Junto a ellas habría recitados y cantos, una charla del compañero Roberto Cotelo a su regreso de España con noticias de la revolución española, y otros compañeros hablarían "sobre tópicos gremiales y de actualidad". También se mostrarían "affiches españoles recientemente llegados", y amenizaría "una buena orquesta". 48

A medida que continuaba la guerra en España las actividades propagandísticas se sucedían a un ritmo mayor, creándose organizaciones barriales y sindicales que preparaban campañas de recolección

40 Ibid., 9/12/1938, p.2.

${ }_{41}$ Ibid., 8/7/1938, p.3; Ibid. 16/12/1938, p.2.

42 El Sol, Montevideo, $2^{\mathrm{a}}$ semana/1/1936, p.3.

43 Ibid., $1^{\text {a }}$ semana/9/1936, p.2.

${ }^{4}$ Ibid., $1^{\text {a }}$ semana/11/1936, p.1.

45 Ibid., $4^{\mathrm{a}}$ semana/5/1937, p.4.

46 Ibid., $2^{\text {a }}$ semana/3/1937, p.2.

47 El Obrero Gráfico, Órgano del Sindicato de Artes Gráficas, Montevideo, enero 1938, p.1.

${ }^{48}$ Idem. 
de fondos y ayuda en especie para las fuerzas actuantes en España. Por ejemplo, el "Sub Comité de Reducto" realizó una "velada de cine" el 6 de julio de 1938 en el Cine Lutecia a beneficio de la CNT española. ${ }^{49}$ Los amigos del periódico anarquista Voluntad organizaron para el 5 de noviembre del mismo año en el Cine Teatro Edén del Cerro una "velada artístico-cinematográfica" en la que hablaría sobre España el "compañero Cotelo". ${ }^{50}$ Roberto Cotelo, uno de los artífices del periódico La Batalla -editado de 1915 a 1927- y fundador de la Unión Sindical Uruguaya (USU) en 1923, estuvo en la España en guerra durante 1937, conectado con las organizaciones libertarias y la CNT-FAI, y colaboró con el periódico Tierra y Libertad de Barcelona. A su regreso a Uruguay, a fines de 1937, continuó participando como representante de CNT y FAI en la región rioplatense, y de "Solidaridad Internacional Antifascista" fundada por los libertarios para organizar la solidaridad a nivel mundial. ${ }^{51}$

Al mismo tiempo continuaban las tareas solidarias a nivel nacional como las campañas por la liberación de los "presos sociales". La velada de la "Agrupación Sembrando Ideas" se hizo para apoyar a los presos en el cine teatro Edén del Cerro, y contó con una "Sinfonía", luego la "apertura" por un compañero, seguido del "film trágico" de Paramount "Caras olvidadas". Continuó la actuación de "un cantor de versos con guitarra", y luego un segundo film, "Silencio", la historia de un hombre puesto "fuera de la ley por no denunciar a su hija". Fue una "entrada general" a $\$ 0.30$. El sábado 29 de abril de 1939, meses antes del inicio de la guerra, en ocasión de rememorar el Primero de Mayo, el Centro Cultural Obrero de 'Estudios Universales' organizó una "función de cine" en el Cine Edén del Cerro. Tuvo el mismo precio que la recién referida, sin diferenciar sexos o edad. ${ }^{52}$

El estallido de la guerra en Europa -luego "Segunda Guerra Mundial"- a comienzos de setiembre de 1939 generó una nueva coyuntura con cambiantes realineamientos al cabo de sus dos primeros años: del inicial pacto germano-soviético y el "neutralismo" de EEUU, se procesó el ingreso de la URSS en junio de 1941 y en diciembre del mismo año de los EEUU al campo bélico "aliado", implicando una modificación para las izquierdas, de los bloques y posturas políticas al interior del país, y un mejoramiento de sus relaciones entre aquellas.

A partir de 1942 fueron muy frecuentes las funciones de cine soviético ancladas en el género bélico y ligadas directamente a la propaganda y el esfuerzo de guerra pro-aliado y pro-URSS. Esto revelaba que los comunistas ya habían procesado el cambio desde el formato "velada" a los "festivales" de cine, fundamentalmente brindando filmes de guerra y de tono epopéyico soviético y de propaganda de la vida y realizaciones de la URSS. En una parte significativa de sus actividades utilizaron, además de los locales partidarios, cines céntricos y barriales. En diciembre de 1942 un aviso publicitario invitaba a presenciar "24 días en la Unión Soviética" en el Ariel. ${ }^{33}$ Un par de semanas más tarde otro aviso indicaba que se ofrecía un doble programa de películas de origen soviético en el Astor en la Aguada, la citada "24 horas ..." y "La Canción del Volga". ${ }^{54}$ Eran funciones contratadas por el PC para obtener finanzas y propagandear los contenidos políticos y antifascistas de los films. Se anunciaba nuevas funciones de cine para el 3 de febrero, que incluía "Camaradas" en el Cine Astor "a beneficio del PC" y la ya estrenada " 24 horas ...". ${ }^{55}$ Este uso del cine revela el interés comunista en difundir los logros de la Unión Soviética -incluido el heroísmo de su pueblo- y de afianzar la defensa de su modelo social y político.

Si se observa las formas culturales del "tiempo libre" de los anarquistas se puede reconocer que estaban en un momento de cambios. Esto se puede relacionar con la aún incipiente tensión que ocurría

\footnotetext{
49 Voluntad, Órgano de la Agrupación Anarquista Voluntad, Montevideo, junio 1938, p.3.

50 Ibid., agosto1938, p.4.

51 Rodolfo Porrini, "Uruguay y la guerra civil. Una retaguardia caliente", en Brecha, Montevideo, 28/7/2006, Suplemento 70 años de la guerra civil española, p.3.

52 Voluntad, 27/4/1939, p.2.

53 Justicia, 11/12/1942, p.4.

54 Ibid., 8/1/1943.

${ }^{5}$ Ibid., 15/1/1943, p.4.
} 
en el terreno doctrinario y en sus organizaciones, proceso que se haría más visible a mediados de los años cincuenta con la fundación de la organización "específica” Federación Anarquista Uruguaya (F.A.U.). De los 21 eventos culturales anarquistas "en espacios cerrados" registrados entre 1938 y 1944 , diez contaron con proyecciones de cine, nueve con teatro, seis con conferencias, le seguían música (4), recitado y poesía (3) y canto (3). Esto mostraba un progresivo cambio en el formato de la velada y en la primacía de sus componentes -el cine desplazando las artes escénicas y musicales-, lo que también se puede ver en las denominaciones, haciéndose más frecuente el "festival" y la "función" frente a la clásica "velada". Posiblemente, lo que las fuentes consultadas no enseñan, pero se puede deducir, es que no faltó la "palabra" ni la "oratoria" de las conferencias o arengas, tal vez viró en algo más acotado y lateral, no necesariamente menos eficaz. Al mismo tiempo, es difícil conocer la "experiencia" que cada obrero u obrera, militante o simpatizante vivió en el acto cultural, en la asistencia, en la previa decisión de participar o no, en el efecto en su "conciencia" o en sus deseos al terminar el festival y soportar o disfrutar el tiempo transcurrido.

En esos años durante la guerra, los grupos ácratas desarrollaron una actividad cultural importante, proponiendo obras teatrales, películas o conferencias que apuntaban a mostrar críticamente aspectos del capitalismo, a efectuar la solidaridad internacional con los perseguidos o a rememorar las efemérides clásicas del movimiento obrero, sin entrar en la campaña "pro aliada" mayoritaria en la sociedad uruguaya, a la que buscaron eludir o denunciar al caracterizar la situación como de "sangrienta guerra imperialista". En su repertorio teatral tomaban textos y obras dramáticas y de crítica social provenientes de varones ácratas rioplatenses como Rodolfo González Pacheco ("Hijos del Pueblo") o Florencio Sánchez y españoles como Ramón J. Sender ("El Secreto”) y Joaquín Dicenta ("Juan José”), y poesías que tenían un compromiso ideológico con la postura antibelicista y antipatriota. Las conferencias apelaban al saber médico y por ejemplo identificaban algunos de los males del capitalismo aun vigentes como el flagelo de la tuberculosis entre los sectores populares.

Los nuevos grupos anarquistas como Juventudes Libertarias y la Casa de los Libertarios surgidos hacia 1938, tendieron a promover actividades en las que incluían cine. Estas funciones por lo general se desarrollaron en barrios de trabajadores, casi nunca en el centro de la ciudad, tal vez por la implantación más territorial de los grupos que los promovían y su intención localizada en esos ámbitos. Entre los films se destacaban los de origen francés y también alguno argentino. Una cartelera de actividades anunció para el 23 de agosto de 1939 en el cine La Lira un "festival cinematográfico" de la FORU y a su beneficio. ${ }^{56} \mathrm{El}$ Comité Sindical de Acción Libertaria organizó una función a su beneficio en agosto de 1940 en el Cine Paso del Molino. En el doble programa se exhibió las películas francesas "Yo Acuso" (1938) y "El hombre que reclamó su cabeza". ${ }^{57} \mathrm{La}$ importancia de esta función era precisamente el posicionamiento contrario a la guerra en curso -luego de la caída de París y el fin de la "guerra boba"-, donde era cada vez más difícil mantenerse "neutrales". En coherencia con las películas entre ambas se escucharían "las palabras por un compañero de la significación del acto". Mientras el primer film refería a la guerra de 1914 y se presentaba como un "emocionante alegato contra las guerras", el otro mostraba "el grito desgarrador" de las madres, las viudas y los mutilados de la guerra europea, como una "advertencia" para los gobiernos.

En 1942 fueron proyectados otros films en el Lutecia (barrio Figurita) como el francés "Amanece" (1939) de Marcel Carné, y el argentino "Kilómetro 111" (1938) un drama de Mario Soffici con toques sociales, crítico del papel de los acopiadores e intermediarios entre los agricultores y los exportadores. ${ }^{58} \mathrm{Al}$ año siguiente un "festival" en el Cine American -en el barrio Cordón- reunía los films franceses "La gran ilusión" (1937), de Jean Renoir sobre prisioneros franceses en un campo

\footnotetext{
56 Voluntad, agosto 1939, p.5.

${ }^{57}$ Ibid., $2^{a}$ quincena julio 1940, p.3.

${ }^{58}$ Ibid., julio 1942, p.3.
} 
alemán y su intento de fuga, y "El muelle de las brumas" (1938) de Marcel Carné, que relata la historia de un desertor del ejército francés. ${ }^{59}$

Con el fin de la Segunda Guerra, un ambiente festivo y de expectativas se apoderó de Montevideo y también en gran parte de las organizaciones de izquierda y los sindicatos. En los eventos comunistas fue evidente que además de festejar, como todos, el fin de la guerra, saludaban el fundamental influjo mundial de su patria-modelo la URSS. En ocasión del "festejo aniversario" de la Revista comunista Nosotras en febrero de 1946 se realizó un festival que abarcó un nutrido Programa, desde la oratoria y la poesía - de varios comunistas uruguayos- hasta la culminación con un "espectacular" baile. Luego de los discursos políticos -la Administradora de la Revista y el Secretario General del PC, Eugenio Gómez- se escucharon el recitado de un "Romance a Miguel Hernández", "Canción de cuna" de Atahualpa del Cioppo interpretado por su autor, entre otros poemas. Luego de la "clausura" de la parte oratoria por la Secretaria de Redacción, la Segunda Parte consistía en un "Gran baile amenizado por el conjunto típico "George". ${ }^{60} \mathrm{El}$ precio era diferenciado, para "caballeros" \$0.70 y las "damas" gratis. En mayo del mismo año desde Nosotras se invitaba a un "Gran festival de cine del Comité Departamental del P. Comunista" con un triple programa de films soviéticos. ${ }^{61}$

En 1947 los sindicatos y asociaciones comunistas mostraron un énfasis definido en las actividades bailables, particularmente visible en el periodo de carnaval, lo que era entendible. Pero evidenciaba también una predilección y un gusto por ellos, pues en paralelo disminuía la exhibición de cine en sus festivales, aunque los films soviéticos siguieron proyectándose por un tiempo en los cines del circuito comercial. El sábado 15 de marzo, en días de carnaval, el Centro de Obreros Gráficos -una escisión comunista del Sindicato de Artes Gráficas- programó un "baile de disfraces" con entrada libre para los afiliados. Por otra parte, el Centro Cultural Máximo Gorki, de origen ruso, hizo otro baile "por invitación" en un local céntrico, así como la Agrupación comunista de funcionarios de la UTE un "gran festival" con baile. Para rematar Justicia y el PCU realizaron un "gran festival bailable" en su local central en Sierra 1720, con premios al "mejor disfraz". ${ }^{62}$

Un "Gran Festival" organizado a beneficio de los "niños españoles refugiados en Francia" era también bailable, recordando a las veladas por la importante presencia de las comunidades inmigrantes y sus expresiones culturales. Estuvo organizado por dos instituciones femeninas pro-comunistas y se realizó en la Casa de Galicia. El festival tenía números de canto y "danzas españolas". ${ }^{63}$ También en esos días, con el objetivo de recaudar fondos "para pagar deudas" por las últimas elecciones y financiar "un gran acto público en Maroñas" pro Seguro de Paro de los textiles, los comunistas del Seccional 11 organizaron un "festival cinematográfico". Allí se exhibiría "La Preferida" y "Juramos volver", este último "el épico film soviético que por primera vez se dará en esta zona". ${ }^{64}$

En 1950 un Seccional del PC -la 18 y la 24a - anunciaba su "festival artístico" para el sábado 18 de marzo "con motivo de la formación del aparato de finanzas", sin más datos de la actividad. ${ }^{65}$ En el marco del inicio del Campeonato de Fútbol 1950 -comunista-, la comisión organizadora preparaba para el 9 de abril y desde las 17 y 30 horas un "Gran Festival artístico bailable" y una "Conferencia sobre el Deporte en el Partido". ${ }^{66}$ La conjunción del "baile" y el "cine" y "lo artístico" nunca se abandonaba, pero adquiría nuevos perfiles según se vinculara con la actividad de un seccional en un barrio, en el terreno de su "campo deportivo" o en las grandes escenarios de masas que el "Partido" estaba llamado a convocar y "a conquistar".

59 Ibid., abril-mayo 1943, p.4.

${ }^{60}$ Diario Popular, Montevideo, 22/2/1946, p.4.

61 Nosotras, Montevideo, mayo 1946, p.17.

62 Diario Popular, 15/3/1947.

${ }^{63}$ Ibid., Montevideo, 4/3/1947, p.2.

${ }^{64}$ Ibid., 14/3/1947, p.2, Ibid., 18/3/1947, p.2.

65 Justicia, 17/3/1950, p.5.

${ }^{66}$ Idem. 
El anarquista Juan Carlos Mechoso recordó "Nosotros alquilamos un cine, queda ahí en Agraciada, el Alcázar se llamaba, y ahí se daban películas digamos de tipo social, y a veces había alguna representación teatral corta, cosa así, previa, ... pero algo más combinado que eso yo no me acuerdo de haber visto en el ambiente libertario de ese tiempo". ${ }^{67}$ También señaló que el Ateneo Cerro-Teja tenía su grupo de teatro, lo que mostraba cierta continuidad con la tradición de los antiguos "cuadros dramáticos" casi desaparecidos bajo el desarrollo de verdaderos grupos teatrales, con tendencia a su profesionalización. Eran estos grupos de teatro independiente solidarios con conjuntos no profesionales de los ateneos, a los que ayudaban y asesoraban: "una barra grande venía de La Teja ... un grupo joven, venía Julio Matos a enseñar, que venía del Tinglado, y habíamos hablado con Atahualpa [del Cioppo] de El Galpón, que se había iniciado un año o dos antes, que fue anarquista y después se hizo "bolche". Y que antes de este grupo "había estado un grupo de teatro, ... mi hermano era del grupo de teatro, Alberto, era todo un grupo de La Teja ... El ambiente de teatro estaba en el Cerro, pero la gente provenía de La Teja".

De nueve eventos libertarios organizados entre 1949 y 1952, ocho incluyeron cine, tres contaron con conferencias y sólo una tuvo una representación teatral. La mayoría se denominaban "festival cinematográfico" y "funciones de cine". Los barrios en los que estaban las salas fueron Unión, Belvedere, Cerro, Cordón, Aguada y la zona cercana al Palacio Legislativo. Los films eran franceses, estadounidenses y argentinos, abarcando dramas y críticas sociales, obras de "arte" y "clásicos" como los films de Chaplin, hasta comedias de entretenimiento, supuestamente sin orientación "ideológica". Además del cine "de ideas" que predominaba, el uso del cine "comercial", más liviano o sin "compromiso social" podía ser también indicador de un intento de acercarse a los gustos populares por parte de algunos sectores libertarios. Los objetivos de las funciones y festivales remitían a acciones solidarias y de recaudación de fondos para los comités de apoyo de los presos navales, de la prensa como Voluntad y las recordaciones de los "mártires de Chicago" los Primeros de Mayo. Un festival de cine por el Primero de Mayo de la FORU realizado el 27 de abril de 1949 en un cine en la Unión -el Glugksmann Palace- contó con varias "cintas" que fueron consideradas poco acordes "con los objetivos doctrinarios que perseguimos", aunque considerando "las posibilidades de los organizadores, alcanzaron a satisfacer el interés de los concurrentes". ${ }^{68}$ En esto se estaba reconociendo ambos aspectos, las limitadas "posibilidades" de la organización y "el interés" del público que aceptaba las películas seleccionadas. El "Sub Comité del Pantanoso pro Liberación de los presos navales" hizo una función de cine en mayo del mismo año en el cine Belvedere Palace, ofreciendo dos películas cómicas de Luis Sandrini, "La calles de los conflictos" y "Peluquería de señoras". ${ }^{69}$ Según balance del beneficio se vendieron 831 entradas, número nada despreciable.70 Otra función similar ocurrida dos meses después obtuvo un éxito mayor, vendiéndose casi mil entradas. ${ }^{71}$ En una velada de cine a "beneficio" de Voluntad en el Cine Montevideo en julio dieron "El Rey", película francesa "de crítica social" y "También somos seres humanos", una crítica de guerra. ${ }^{72}$ Una nueva función del Comité del Pantanoso por los presos navales en marzo de 1950 combinó una comedia de Sandrini, "Secuestro sensacional!!!”, con la importante obra de Orson Welles "El Ciudadano". ${ }^{73}$

La "velada" de FORU por el Primero de Mayo de 1950 incluyó la comedia dramática 'Mi primer pleito' de Conrado Rodríguez, representada por un "conjunto de actores y aficionados", luego de la cual el compañero Minotti cerró el acto “con breves palabras alusivas al $1^{\circ}$ de mayo y valorizando

\footnotetext{
${ }^{67}$ Entrevista a Juan Carlos Mechoso, realizada por Rodolfo Porrini, Montevideo, 12/12/2008.

68 Solidaridad, julio 1949, p.5.

${ }^{69}$ Voluntad, mayo 1949, p.1.

70 Proa, Federación Obrera de Construcciones y Reparaciones Navales Autónoma, Montevideo, agosto 1949, p.2.

71 Idem.

72 Voluntad, mayo 1949, p.4.

${ }^{73}$ Ibid., marzo1950, p.3.
} 
el ideal anarquista". ${ }^{74} \mathrm{Al}$ año siguiente la FORU realizó su velada el 27 de abril en el Cine Uruguayo, ofreciendo una función de cine, con "una de Chaplin de carácter reidero" y una película dramática en la Italia bajo el fascismo, titulada "Ante él temblaba toda Roma". Solidaridad comentó que se reunieron allí "un gran número de camaradas con sus familiares" y el programa "dentro de las posibilidades", resultó interesante. ${ }^{75}$ Aunque la FORU decrecía su influencia social, un "balance de la velada del 27 de abril" revelaba la venta de 423 entradas, manteniendo un grupo relativamente estable, y una posible adaptación que reconocía los cambios: la casi total sustitución de las antiguas formas por el ahora omnipresente cine. La celebración por la FORU en 1952 tuvo el mismo esquema: "Un programa cinematográfico, [cuyas películas] gustaron, en cuyo intervalo un compañero hizo uso de la palabra". ${ }^{76}$

\section{Conclusiones}

En este trayecto temporal, las veladas, tan potentes en el inicio de este estudio -en los años veinte y parte de los treinta- fueron declinando y al mismo tiempo transformándose, en sus formas expresivas y hasta en su denominación. Este cambio se fue insinuando desde la referencia cada vez más común a los "festivales", "funciones" y "bailes", frente a las cada vez más extrañas "veladas". La transformación fundamental fue la composición de los géneros que aquellas incluían, posiblemente moldeadas por la influencia de cambios mayores en la sociabilidad montevideana y en los medios de comunicación. Si recordamos la imagen de la velada "artístico-musical" con teatro, poesía, canto, además de la oratoria y los himnos, se llega a fines de los cuarenta con "funciones cinematográficas" en la que la palabra era un breve discurso en el entreacto entre la proyección de dos filmes. La otra modalidad que fue creciendo desde los veintes fue el "festival" básicamente bailable -diversos tipos de bailes regionales y juveniles- hasta arribar a una escena centrada y diferenciada en los "bailes" que se consolidó entre los comunistas especialmente. En las otras corrientes era común hacer bailes en los paseos campestres donde la "orquesta" era una atracción fundamental.

En paralelo y posiblemente como factores que influyeron en estos cambios podemos pensar en las nuevas formas de sociabilidad: la masividad y "popularidad" mixta de los bailes y a las barriales matinées de cine, y la persistencia de la asistencia exclusivamente masculina al boliche. Y como novedoso también, la implantación o explosión de nuevos medios de comunicación masivos en Montevideo, como la radio, las revistas "populares" y el cine, o expresiones como los "teatros independientes" que renovaron el teatro y su público. Estos medios modificaron las ofertas para el "tiempo libre" y acicatearon conciente o inconcientemente a los "organizadores" de izquierda, sindicatos y otras organizaciones populares, llevándolos a incorporar crecientemente el cine, y ocurriendo el desplazamiento de las representaciones teatrales hacia los "teatros independientes", la disminución y la casi desaparición de su uso en festivales y veladas. Al mismo tiempo, y en vínculo con la radio -que promovía los ritmos bailables- revistas muy leídas como Cancionera y el mismo cine que creaba la fama de los artistas populares, se imponían los masivos y populares "bailes", poniendo en jaque o desafiando a las izquierdas a considerarlos como una opción más para el "tiempo libre".

A pesar de la hegemonía social y cultural de la burguesía en los años 40 e inicios de los 50 -el "estado de bienestar"-, y de la a veces esquiva cultura popular para las izquierdas, estas persistían en insertarse entre las clases populares y fueron modulando sus propuestas, también las del "tiempo libre". Podría pensarse que se preparaban para la eclosión del decenio siguiente, los conflictivos y esperanzadores años sesenta.

\footnotetext{
74 Solidaridad, agosto 1950 , p.2.

75 Ibid., agosto 1951, p.7.

${ }^{76}$ Ibid., setiembre 1952, p.2.
} 
Podría preguntar ¿cuánto de la construcción cultural alternativa forjada por las izquierdas en las décadas previas, constituirá uno de los componentes ideológicos y de las prácticas disponibles que usarán en los años sesenta? Es decir, planteo la idea hipotética de que algunas de las prácticas y usos de las formas culturales previas estuvieron disponibles como modelos y referentes para los desafíos de las izquierdas internacionales y de la naciente "nueva" izquierda. En particular, puede serlo la imagen que la militancia por la revolución ordenaba la vida de las personas y sus tiempos, como pudo serlo en los años veinte, donde todos los tiempos cobraban sentido en función de la militancia por la transformación social.

Por último, también puede ser motivador de una investigación específica el conocer cómo interactuaban y disputaban las nuevas formas alternativas de las izquierdas con el mundo cultural hegemónico entonces -incluidas las relaciones sexo/género, etáreas y raciales-, en el trabajo y en el "tiempo libre".

\section{Referencias bibliográficas Bibliografía}

Andreu, Jean, Fraysse, Maurice, Golluscio de Montoya, Eva, Anarkos. Literaturas libertarias de América del Sur 1900, Buenos Aires, Corregidor, 1990.

Barrancos, Dora, "Lecturas comentadas. Un dispositivo para la formación de la conciencia contestataria. 1914-1930”, en Educ. Rev., Belo Horizonte (6), pp.45-47, diciembre 1987.

Batalha, Claudio H.M., "Cultura associativa no Rio de Janeiro da Primeira República", en Claudio H.M. Batalha, Fernando Teixeira da Silva, Alexandre Fortes, Culturas de classe. Identidade e diversidade na formaçao do operariado, Campinas, Editora da Unicamp, 2004, pp.95-119.

Camarero, Hernán, A la conquista de la clase obrera, Buenos Aires, Siglo Veintiuno/Editora Iberoamericana, 2007.

de Giorgi, Ana Laura, "Entre la lucha contra la carestía y por los derechos de la mujer. Las comunistas uruguayas durante la segunda mitad del siglo XX (1942-1973) en Adriana Valobra, Mercedes Yusta (eds), Queridas camaradas. Historias iberoamericanas de mujeres comunistas, Buenos Aires, Miño y Dávila Editores, 2017, pp.215-234.

Fontes, Paulo, Um Nordeste em Sâo Paulo, Rio de Janeiro, FGV Editora, 2008

Fortes, Alexandre, Nos do Quarto Distrito, Rio de Janeiro, Garamond, 2004

Hobsbawm, Eric, El mundo del trabajo, Barcelona, Crítica, 1987.

Hoggart, Richard La cultura obrera en la sociedad de masas, México, Grijalbo, 1990

Lobato, Mirta, La vida en las fábricas, Buenos Aires, Prometeo Libros/Entrepasados, 2001.

Porrini, Rodolfo, "Uruguay y la guerra civil. Una retaguardia caliente", en Brecha, Montevideo, 28/7/2006.

Porrini, Rodolfo, "Izquierda uruguaya y culturas obreras en el 'tiempo libre’: Montevideo (1920-1950)", Tesis de Doctorado, UBA, 2012, inédita.

Sapriza, Graciela, Memorias de rebeldía. Siete historias de vida, Montevideo, Puntosur Editores, 1988; Hilamos una historia. La memoria sindical desde las mujeres, Montevideo, CIEDUR, 1989, pp.3-57; Los caminos de una ilusión. 1913 Huelga de mujeres en Juan Lacaze, Montevideo, Fin de Siglo, 1993.

Stedman Jones, Gareth, "¿Expresión de clase o control social? Crítica de las últimas tendencias de la historia social del 'ocio"' en Lenguajes de clase. Estudios sobre la historia de la clase obrera inglesa (1832-1982), Madrid, Siglo XXI, 1989, pp.72-85.

Suriano, Juan, Anarquistas. Cultura y política libertaria en Buenos Aires 1890-1910, Buenos Aires, Manantial, 2001.

Taks, Javier, "La clase trabajadora y la obrera del Anglo" en Revista Encuentros, Montevideo, No6, 1999. Thompson, Edward P., La formación de la clase obrera en Inglaterra, Barcelona, Crítica, 1989. 
Thompson, Edward P., Costumbres en común, Barcelona, Crítica, 1995.

\section{Fuentes}

Periódicos de izquierda y gremiales:

Despertar, Publicación de la Sociedad de Resistencia Obreros Sastres, Montevideo, 1918.

Diario Popular, [Diario oficioso del Partido Comunista], Montevideo, 1946, 1947.

Justicia, Organo del Partido Comunista, Montevideo, 1923, 1924, 1928, 1936, 1942, 1943, 1950.

El Obrero Gráfico, Órgano del Sindicato de Artes Gráficas, Montevideo, 1938.

El Sol, Órgano del Partido Socialista, 1930, 1936, 1937.

Nosotras, "Las mujeres comunistas al servicio de la patria", Montevideo, 1946.

Proa, Federación Obrera de Construcciones y Reparaciones Navales Autónoma, Montevideo, 1949.

Solidaridad, Órgano de la Federación Obrera Regional Uruguaya, Montevideo, 1933, 1949, 1950, 1951, 1952.

Unión Sindical, Órgano de la Unión Sindical Uruguaya, Montevideo, 1930.

Voluntad, Órgano de la Agrupación Anarquista Voluntad, Montevideo, 1938, 1939, 1949, 1950.

Novela y autobiografías:

de Castro, Manuel, Oficio de vivir, Ediciones Banda Oriental, Montevideo, 1959.

Alcoba, María Julia, Las mujeres ¿donde estaban?, Montevideo, Ediciones Primero de Mayo, 2014.

Rouco Buela, Juana, Historia de un ideal vivido por una mujer, Buenos Aires, 1964.

\section{Referencias orales.}

Campistrús, María Julia. Entrevista realizada por Rodolfo Porrini, Montevideo, 27/4/1991.

Mechoso, Juan Carlos. Entrevista realizada por Rodolfo Porrini, Montevideo, 12/12/2008. 